\title{
Germination requirements of the subordinate fen meadow species Valeriana dioica $\mathrm{L}$
}

\author{
Leonid Rasran $(\mathbb{D} \cdot$ Cornelia Eisenmann • \\ Regina Wagentristl • Karl-Georg Bernhardt
}

Received: 29 June 2018 / Revised: 29 May 2019 / Accepted: 16 July 2019/Published online: 16 November 2019

(C) The Author(s) 2019

\begin{abstract}
Plant species of the intermediate life strategy type are characteristic for species-rich grasslands, which are sensitive to changes in the level of disturbance. Germination and early establishment of seedlings is expected to be the most crucial stage, limiting the successful colonization of appropriate sites. Valeriana dioica is a typical plant of calcareous fens, which are dependent on regular suppression of strong competitors by means of moderate land use. It is endangered in many parts of Central Europe, including Lower Austria. We studied the effects of light, temperature and pretreatment (cold stratification) on the germination success of $V$. dioica seeds and the role of litter produced by different competitors on the early establishment of seedlings. We tested seeds from five populations differing in the level of competition for light and considered also the morphological variability of propagules and maternal plants. We found that $V$. dioica is able to germinate without light. It showed high germination percentages both under high summer temperatures independent of cold stratification and at low temperatures, but only after the stratification. Litter produced by dicotyledonous forbs was less hampering for the seedlings than that of small sedges or grasses. Valeriana dioica possesses a broad regeneration niche and is able to use gaps for germination and establishment both in spring and in summer. It reproduces successfully in herb-dominated
\end{abstract}

L. Rasran $(\bowtie) \cdot$ C. Eisenmann · R. Wagentristl •

K.-G. Bernhardt

Universitaet fuer Bodenkultur Wien, Wien, Austria

e-mail: leonid.rasran@boku.ac.at fen meadow vegetation but disappears from reed communities. This study demonstrates the significant plasticity of the regeneration niche for a species with an intermediate life strategy and also stresses the importance of gaps for its reproduction.

Keywords Litter - Light competition · Stratification . Plant strategy Plasticity Seed traits

\section{Introduction}

In semi-natural grassland landscapes of Central Europe, a significant part of species diversity consists of plant species of the intermediate life strategy type (CSR competitive-stress tolerant-ruderal sensu Grime 1974). They contribute to local and regional biodiversity (Cerabolini et al. 2016) and are characteristic for a whole range of plant communities which are of priority for European nature conservation programmes, among others hay meadows (Molinion caeruleae, FFH 6410) and calcareous fens (Caricion davallianae, FFH 7230). In spite of its commonness, the regarded strategy type is often difficult to define based on formal criteria and requires consideration of a broad spectrum of characteristics of plant life history, morphology and phenology (Grime et al. 1988). CSR plants are weak competitors, dependent on moderate levels of disturbance, such as mowing once a year or moderate grazing, but sensitive to intensification of agricultural land use. A further crucial part of their life strategy is generative reproduction, including dispersal, germination and 
establishment, which requires the availability of regeneration niches as a combination of specific conditions allowing the replacement of older plant individuals by new ones originating out of generative propagules (Grubb 1977; Tilman 1988; Shipley et al. 1989).

Before semi-natural grasslands became common in Central Europe as a result of human activities, subordinate species were restricted to a few primary habitats with a significant level of disturbance, available for short time spans. During secondary succession, single populations of these species become extinct and species survival is only secured if new populations occur continuously (e.g. Rosenthal 2010). Thus, a significant component of the regeneration niche is the ability to spread beyond the borders of the current plant community and establish new (sub)populations. Later on, regularly occurring moderate disturbances became the paramount factor for long-term existence of weak competitors at the same location. If regular land use in grassland plant communities is abandoned, weak competitors are the first species to disappear (Schrautzer and Jensen 2004). In consequence, target fen meadow communities turn into species-poor reeds. In typical cases, some subordinate species can still persist for comparatively long periods of time as mature individuals. They even show effective adaptations to changing site conditions, such as shade avoidance, as a reaction to the increasing light competition (Huber and Wiggerman 1997). Eventually, however, populations of these species become extinct in fallow land because of the absence of generative reproduction (e.g. Schrautzer et al. 2011). We face the typical case of (micro) site limitation, stressing the importance of specific gaps for germination and establishment of juvenile plants (e.g. Eriksson and Ehrlén 1992; review by Münzbergová and Herben 2005).

Otherwise, increasing stress caused by stronger competition for light can function as triggers improving the capability for long-distance dispersal and colonization of new sites (overcoming the dispersal limitation). This can be the case by increasing the stem height of maternal plants as a shade avoidance reaction but leading at the same time to an increase of the seed release height. Alternatively, adaptations to higher dispersal ability result in differences in the morphology of fruits. This would correspond to the theoretically postulated equilibrium between high- and low-dispersal (persistent) genotypes within a population (Cohen and Levin 1987; McPeek and Holt 1992) and argues for the flexibility of the regeneration strategy of the species. However, besides a few observations on heteromorphic seeds (Imbert and Ronce 2001; Ma et al. 2017), there are still no reliable tests of this assumption.

We selected Valeriana dioica L. as a typical plant of species-rich fen meadows that follows the intermediate life strategy. It is representative of a large group of the abovementioned subordinate species and can be used as a model object to study their behaviour and reproduction. In contrast to species occurring only in early successional stages (A- and Da-species sensu Jensen and Schrautzer 1999), V. dioica can, after local extinction at abandoned reed sites, appear again in later successional stages of fen forests, for example in alder carrs (Slezák et al. 2013). This presumes adaptations to germination and early establishment under light-limited conditions. We compared five populations of $V$. dioica growing under different levels of light competition to study the interspecific plasticity of adaptations to dispersal and germination.

Dispersal ability was studied by considering fruit morphology and seed release height. The study of germination behaviour included experiments on the reaction to temperature, light and pre-treatment (cold stratification), which are considered the most important parameters regulating seed dormancy and the regeneration niche in general (see Baskin and Baskin 2014). We also considered plant litter as a further crucial component of the regeneration niche, affecting the germination of seeds and especially early establishment of seedlings (e.g. Facelli and Pickett 1991; Facelli and Facelli 1993; Bosy and Reader 1995; Špačková et al. 1998; Galvánek and Lepš 2012). To analyse the effects of litter in the dependence of site conditions, we included besides presence/absence also different kinds of litter occurring at sites with $V$. dioica populations in the experimental setup.

In particular, we focused on the following questions: (1) Do the populations under study differ in plant performance (plant height, seed mass, seed dispersal ability and seed germination)? (2) How do temperature, light and stratification affect the germination of $V$. dioica? and (3) Can litter of different vegetation types hamper the germination and early establishment of $V$. dioica seedlings? 


\section{Material and methods}

\section{Study species}

Our target species Valeriana dioica L. (Valerianaceae), which is commonly called the small marsh valerian, is a perennial, rhizomous hemicryptophyte. It occurs all over Europe (Hegi 2008) in wet and fen meadows, calcareous mires and along riversides. Because of changes in land use (both intensification and abandonment), most populations of $V$. dioica are on the decrease or already extinct. The species is threatened in Central Europe and is regionally endangered (red list status in Lower Austria - Schratt 1990).

The plant propagates both vegetatively and by seeds. Its rhizomes are short and daughter rosettes remain connected to the maternal plant. Fruits are one-seeded achenes with a pappus, primarily adapted to wind dispersal. The germination ability of stored seeds (frozen for 11 months at $-20^{\circ} \mathrm{C}$ ) is noted as $70 \%$, the average seed weight as $0.52 \mathrm{mg} / \mathrm{seed}$ (SID, Royal Botanic Gardens Kew 2018). Under natural conditions, $V$. dioica is expected to form a transient seed bank (Thompson et al. 1997).

\section{Study sites}

Five $V$. dioica populations were examined in Lower Austria and Burgenland. The selected populations were of sufficient size to obtain enough seeds necessary for the germination experiments. Furthermore, only sites where conservation authorities allowed the interventions were used. The first population (Pottenbrunn PO) was situated in a calcareous spring fen area close to the town of Sankt Pölten. The next three populations (Glasgrabenwiese - LG, Schöne Wiese - LS and Waldwiese - LWW) were located in wet meadow patches surrounded by deciduous forest within the 'Vienna Woods' mountains near Lainz. The last population (Neusiedler See - NS) was a calcareous fen close to Lake Neusiedl (Fig. 1; see Table 1 for more details). The most distant populations, PO and NS, were situated about $90 \mathrm{~km}$ from each other and 40 and $55 \mathrm{~km}$ away, respectively, from the populations in the Vienna Woods. The populations LG, LS and LWW were situated within a radius of about $1 \mathrm{~km}$, isolated from each other by forested areas. The climate of the study sites is warm temperate. The site NS is situated in the Pannonian climate region and is therefore dryer and warmer than the others (see Table 1). The vegetation density and level of light competition for $V$. dioica at the study sites was characterized by measuring the relative light availability at different heights $(0,15,30,45$ and $60 \mathrm{~cm}$ above the soil surface; RL0 - RL 60) with the help of a SunScan Device (Delta-T). We considered the average relative light availability as the percentage of full light at $15 \mathrm{~cm}$ above the soil surface (RL15; mean of at least fifteen measures per site) a proper value characterizing the light climate. On each site we also recorded the average height of generative ramets of $V$. dioica (seed release height) as the main parameter of maternal plants affecting the dispersal ability.

The $V$. dioica population of PO was situated within two adjacent vegetation types: a wet meadow dominated by dicotyledonous herbs, namely Cirsium oleraceum (L.) Scop., Filipendula ulmaria (L.) Maxim. and Sanguisorba officinalis L., and a small sedge community with Carex flacca Schreb., C. panicea L., C. davalliana $\mathrm{Sm}$. and Sesleria uliginosa Opiz. The population density of $V$. dioica (8-10 flowering plants per $\mathrm{m}^{2}$ ) and light availability (RelL15-value between 40 and $60 \%$, with average of $51 \%$; see Table 1) were similar between the two plant communities and allowed us to consider the whole site as one population of $V$. dioica. Differences between the wet meadow and the small sedge community were considered later in the litter experiment (see below).

The populations of $V$. dioica in the area of Lainz grew under different conditions, including sites with strong (in the partly abandoned eutrophic wet meadow of LG) and weak light competition (in the regularly mown small sedge reed of LS). However, the litter cover at LG was comparatively low (not more than $10 \%$ ) versus $30-40 \%$ at the LS and LWW sites. At LS, the entire vegetation was not taller than $15-20 \mathrm{~cm}$, with the exception of a few Phragmites culms. The site LWW could be seen as intermediate between the other two sites. LWW is characterized as a species-rich hay meadow with RelL15-values between 20 and 60\%, caused by high heterogeneity, but mean light availability of about $45 \%$ for the most $V$. dioica plants.

The population at NS was surrounded by tall but less dense vegetation of a calcareous reed stand, including some plants of Cladium mariscus (L.) Pohl. This site was mown regularly and reed species never reached any significant dominance. The litter layer was comparatively strongly developed and contained mainly Cyperaceae species. 


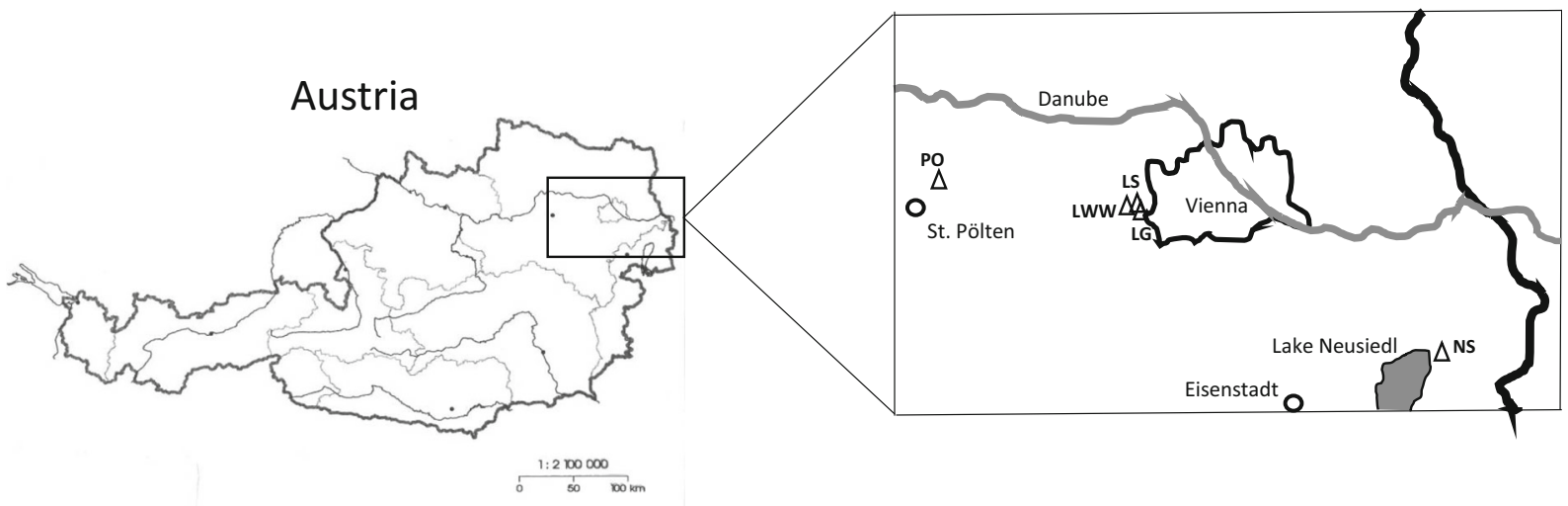

Fig. 1 Locations of the five study populations in Lower Austria (PO, LWW, LS, LG) and Burgenland (NS).

Ripe seeds of $V$. dioica were manually collected from the maternal plants in June 2017 and stored dry at room temperature until the beginning of the germination tests in September 2017. From each population, ten replications of 100 seeds were weighed for the determination of mean seed weight. Seed morphology was studied by measuring the length, width and length of plume hairs for 150 seeds from each population by means of an eyepiece micrometer in a Stemi DV4Stereomicroscope (Zeiss). We assumed the flight ability of achenes to be dependent on the relationship between the seed (embryo) size and size of the flight organ (pappus). This value, calculated as length $\times$ width / pappus diameter, was used for the comparisons below.

Germination tests

\section{Test for favoured germination conditions}

In this experiment, seeds of a single population (NS) were used. We applied a full factorial designed test with two variants of each of three factors: (i) pre-treatment (cold stratification) - yes/no, (ii) two different temperature/day length regimes, 'spring' and 'summer', and (iii) two light regimes, full light and darkness (Fig. 2). For each of the eight possible combinations of the three factors, ten replicates ( 25 seeds per Petri-dish of $90 \mathrm{~mm}$ diameter with filter paper Type 601A) were used. For the pre-treatment (cold stratification), Petridishes were, after watering, placed in the cooling chamber at $3^{\circ} \mathrm{C}$ for six weeks whereas Petri-dishes for the opposite treatment (no stratification) were stored dry at room temperature. In the next step, the Petri-dishes were transferred to a versatile environmental test chamber (Panasonic MLR-352) with programmable temperature and light conditions. 'Spring' conditions consisted of a $15 / 5^{\circ} \mathrm{C}$ and $12 / 12-\mathrm{h}$ light/dark rhythm and 'summer' conditions consisted of a $25 / 15^{\circ} \mathrm{C}$ and $15 / 9$-h light/ dark rhythm. The full darkness treatment was applied by wrapping the Petri-dishes in several layers of aluminium foil so that only daily temperature fluctuations affected the seeds whereas the full light treatment remained open to the illuminants in the test chamber. The examination of the germinating seeds in the 'darkness' treatment was performed in a dark chamber using a narrow spectrum green LED light (with a wavelength of about $550 \mathrm{~nm}$ ) to avoid the triggering of germination by the light impulse during counting.

During the incubation time of 21 days, germinating seeds were counted and removed daily. The viability of remaining seeds was tested by a tetrazolium test $(1 \%$ 2,3,5-triphenyl-tetrazoliumchlorid solution - TTC; Cottrell 1947). Viable embryos turn red or pink after TTC treatment because of their metabolic activity.

\section{Test for differences in germination between populations}

In this test the germination of seeds from all five populations under study was tested under the optimum germination conditions according to the results of the previous test (germination after cold stratification, open for light and temperature regime 'summer', with a $25 / 15^{\circ} \mathrm{C}$ and 15/9-h day/night rhythm). An investigation under varying conditions was not possible because of the restricted number of seeds available from the smaller populations. Twelve replicates (Petri-dishes) with 25 seeds each were used for the five populations. The incubation period was again 21 days, and the remaining seeds were finally tested with the TTC solution for viability (see Test 1 ). To compare the velocity of 
Table 1 Study sites and source populations of Valeriana dioica. Presented are the vegetation (main competitors), light availability as percentage of full light at 15 and $60 \mathrm{~cm}$ above the soil, and height of maternal plants $(\mathrm{cm}) . S D$ - standard deviation.

\begin{tabular}{|c|c|c|c|c|c|}
\hline Locality & Siebenbründl (Pottenbrunn) & Glasgrabenwiese & Schöne Wiese & Waldwiese & Neusiedl \\
\hline signature & $\mathrm{PO}$ & LG & LS & LWW & NS \\
\hline Coordinates $\mathrm{N}$ & $48^{\circ} 13^{\prime} 45^{\prime \prime}$ & $48^{\circ} 11^{\prime} 15^{\prime \prime}$ & $48^{\circ} 11^{\prime} 31^{\prime \prime}$ & $48^{\circ} 11^{\prime} 08^{\prime \prime}$ & $47^{\circ} 56^{\prime} 01^{\prime \prime}$ \\
\hline Coordinates E & $15^{\circ} 41^{\prime} 07^{\prime \prime}$ & $16^{\circ} 11^{\prime} 57^{\prime \prime}$ & $16^{\circ} 11^{\prime} 41^{\prime \prime}$ & $16^{\circ} 11^{\prime} 55^{\prime \prime}$ & $16^{\circ} 51^{\prime} 15^{\prime \prime}$ \\
\hline $\begin{array}{l}\text { Average } \\
\text { temperature } \\
{\left[{ }^{\circ} \mathrm{C}\right]}\end{array}$ & $9.2 *$ & $9.2 * *$ & $9.2 * *$ & $9.2 * *$ & $10.1 * * *$ \\
\hline $\begin{array}{l}\text { Average } \\
\text { precipitation } \\
{[\mathrm{mm}]}\end{array}$ & $659^{*}$ & $741.5 * *$ & $741.5 * *$ & $741.5^{* *}$ & $574 * * *$ \\
\hline $\begin{array}{l}\text { Mean vegetation } \\
\text { height }[\mathrm{cm}]\end{array}$ & 35 & 30 & 15 & 30 & 50 \\
\hline $\begin{array}{l}\text { Maximum veg. } \\
\text { Height }[\mathrm{cm}]\end{array}$ & 80 & 50 & 50 & 75 & 90 \\
\hline Veg. Cover [\%] & 90 & 80 & 60 & 60 & 60 \\
\hline Veg. type & wet meadow & $\begin{array}{l}\text { eutrophic wet } \\
\text { meadow }\end{array}$ & $\begin{array}{l}\text { small sedge } \\
\text { community,invaded by reed }\end{array}$ & $\begin{array}{l}\text { hay } \\
\text { meadow }\end{array}$ & calcareous reed \\
\hline $\begin{array}{l}\text { Dominant plants } \\
\text { (main } \\
\text { competitors) }\end{array}$ & $\begin{array}{l}\text { Cirsium oleraceum (L.) } \\
\text { Scop., Filipendula } \\
\text { ulmaria (L.) Maxim., } \\
\text { Sanguisorba officinalis } \\
\text { L. }\end{array}$ & $\begin{array}{l}\text { Alopecurus pratensis } \\
\text { L., Deschampsia } \\
\text { cespitosa agg., Poa } \\
\text { trivialis L. s. } l .\end{array}$ & $\begin{array}{l}\text { Carex flacca Schreb., Carex } \\
\text { distans L., Carex tomentosa } \\
\text { L., Phragmites australis } \\
\text { (Cav.) Trin. ex Steud. }\end{array}$ & $\begin{array}{l}\text { Molinia } \\
\text { caerulea } \\
\text { agg., } \\
\text { Carex } \\
\text { hirta L. }\end{array}$ & $\begin{array}{l}\text { M. caerulea, } \\
\text { Typha } \\
\text { angustifolia L., } \\
\text { Cladium } \\
\text { mariscus (L.) } \\
\text { Pohl }\end{array}$ \\
\hline Litter cover $[\%]$ & 10 & 10 & 30 & 40 & 40 \\
\hline $\begin{array}{l}\text { Mean relative } \\
\text { light } 15 \mathrm{~cm} \pm \\
\text { SD }\end{array}$ & $51 \pm 6.5$ & $27.5 \pm 6.5$ & $64.6 \pm 6.3$ & $43.9 \pm 14.3$ & $51.3 \pm 16.1$ \\
\hline $\begin{array}{l}\text { Rel. light } 60 \mathrm{~cm} \pm \\
\quad \mathrm{SD}\end{array}$ & $79.8 \pm 4.0$ & $92.7 \pm 2.2$ & $86.8 \pm 4.2$ & $87.0 \pm 2.7$ & $77.7 \pm 15.4$ \\
\hline $\begin{array}{l}\text { Estimated no. of } \\
\quad V . \text { dioica } \\
\text { individuals per } \\
\mathrm{m}^{2}\end{array}$ & $8-10$ & $1-2$ & $2-3$ & $8-10$ & $3-4$ \\
\hline $\begin{array}{l}\text { Mean height }[\mathrm{cm}] \\
\text { of generative } \\
\text { V. dioca } \\
\text { individuals } \pm \\
\text { SD }\end{array}$ & $39.6 \pm 14.4$ & $71.1 \pm 28.3$ & $30.9 \pm 9.3$ & $47.0 \pm 14.8$ & $42.0 \pm 10.2$ \\
\hline
\end{tabular}

Data of the meteorological station: * Sankt Pölten; ** Mariabrunn, Vienna; *** Neusiedl am See

germination between populations, we calculated a modified Timson's index (Baskin and Baskin 2014). Timson's index was calculated as follows: $\Sigma G / t$, where $G$ is the cumulative daily germination percentage and $t=$ 21 is the germination test duration.

\section{Test for germination under the litter layer}

In this test, germination and establishment of seedlings under a litter layer were studied. We harvested plant material from three sites within the area of
Pottenbrunn (PO) in late summer 2017. The first site was a wet meadow composed mainly of dicotyledonous forbs, the second was a small sedge community and the third was a Phragmites australis (Cav.) Trin. ex Steud reed. Valeriana dioica plants were observed within the wet meadow and small sedge community, but not within the reed stand. The harvested material was dried to constant weight, cut in pieces (5-10 cm long) and regarded as litter for the experimental setup. Twenty-five seeds of $V$. dioica per replicate were fixed on a thin square 


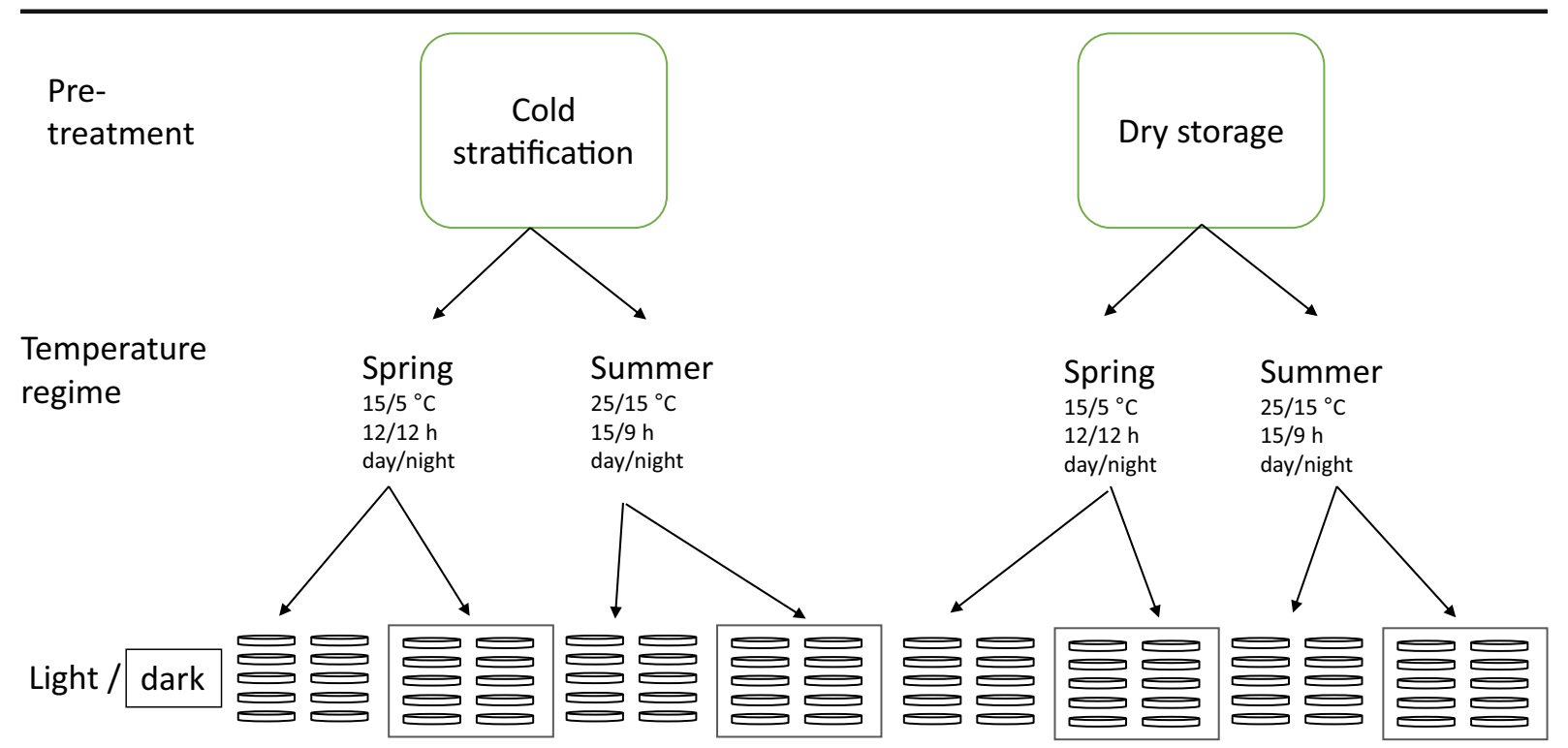

Fig. 2 Design of the three-factorial germination test including factors: (i) pre-treatment (cold stratification), (ii) two different temperature/day length regimes - 'spring' and 'summer', and (iii) two light regimes - full light and darkness. Ten replications

cellulose filter and placed on the soil surface in plastic garden pots $10 \times 10 \mathrm{~cm}$ in size, which were filled with TKS 2 garden soil (Torfkultursubstrat; high nutrition level; (CFloragard). We used 65 pots (13 replicates for each of the five $V$. dioica populations; PO, LG, LS, LWW, NS) per treatment, arranged randomly into a connected surface, where a litter layer was spread. Four litter treatments were applied: open control (no litter), herb litter (300 g dry weight per $\mathrm{m}^{2}$ ), small sedge litter (300 g dry weight $\mathrm{m}^{2}$ ) and reed litter (600 $\mathrm{g}$ dry weight per $\mathrm{m}^{2}$ ). Litter quantities were chosen in accordance with the amount of plant litter observed at the study sites in PO (thus, for the reed treatment the litter layer was twice as thick, as for the wet meadow and small sedge community treatments). All pots were positioned for four weeks, from December 2017 to January 2018, in a so-called grid house (open fence barn) located in the botanical garden of the University of Natural Resources Vienna. During this time period the temperature in the grid house fluctuated between 14.8 and $-4.8^{\circ} \mathrm{C}$, and there were several rain and snow events, so near-natural conditions of temperature and moisture for seed stratification and litter decomposition prevailed. Afterwards, the entire experimental setup was transferred to a glasshouse (temperature $15 / 25^{\circ} \mathrm{C}$ ) for six more weeks and
(Petri-dishes) with 25 seeds each were used for every treatment combination. After collection in July 2017, the ripe seeds were stored dry at room temperature for three months until the beginning of the tests in September.

watered regularly. At the end of the test, the litter layer was removed and all surviving seedlings were counted.

\section{Data analyses}

For the study of seed morphology we used nonparametric Kruskal-Wallis tests analysing differences between the populations studied. We calculated the bivariate correlation (Pearson's correlation) between different seed morphology parameters (seed size, seed weight and pappus diameter). To study the effects of environmental conditions (stratification, light and temperature; test for favoured germination conditions), we applied generalized linear models (GLM) with Gaussian distribution. The three main factors (stratification, temperature regime and light) were treated as fixed factors in the models. We also applied linear mixed models (LMM) with Gaussian distribution for calculating the effects of litter and seed origin (germination tests for different populations and under litter layer, population and litter are treated as fixed factors). Differences between sites were analysed applying pairwise post-hoc tests (parametric: Tukey HSD; non-parametric: KruskalWallis multiple comparison of $P$-values in cases where the ANOVA assumptions were not satisfied). We performed the statistical analyses using $\mathrm{R}$ software for 
statistical computing ( $\mathrm{R}$ Development Core Team 2018).

\section{Results}

Seed release height, seed morphology

Seed release height varied significantly between the plants of five populations studied (Fig. 3A). The smallest stems were found at LS, corresponding to the comparatively low vegetation height and density whereas the highest stems of $V$. dioica could be found at the site LG (most dense vegetation, lowest light availability at $15 \mathrm{~cm}$; Table 1). Mean seed weight differed between $0.5 \mathrm{mg} / \mathrm{seed}$ for plants from PO and NS to $0.7 \mathrm{mg}$ for plants from LG (Fig. 3B). Seed weight was clearly positively correlated with seed size (Pearson's $r=$ 0.4814 ), but there was nearly no correlation between the weight of achenes and the size of the pappus $(r=$ 0.0285 ), and even less correlation between seed size (length $\times$ width) and pappus size $(r=-0.0013)$. We found only slight (not significant) differences in flight ability between populations. Only the seeds from LG differed significantly from those from other populations (Fig. 3C).

Favoured germination conditions

The three regarded factors had different effects on the germination percentage of $V$. dioica seeds. The effect of light availability was low. The seeds were able to germinate also without light. In some temperature and pretreatment regimes, the germination percentage of seeds kept in the dark was even greater than of seeds kept in the light (differences not significant). Both the pretreatment (cold stratification) and higher temperature with long day periods increased the germination percentage significantly, although the effect of the pre-treatment was less important $(P<0.01)$ than that of temperature $(P<$ $0.001)$. We noticed a highly significant $(P<0.001)$ interaction between the factors 'temperature regime' and 'pretreatment'. Generally, under high temperatures and a long daylight period of incubation, significantly more seeds germinated in comparison with low temperatures. However, under treatments with cold stratification, the germination percentage at low temperatures was nearly the same as under high temperatures (Fig. 4). Interactions between light and pre-treatment were not significant, and between light and temperature they were only slightly significant with $P<0.05$. The TTC test showed that the percentage of still viable but not germinated seeds in all treatments was comparatively low and nearly equal. Thus, GLM models, calculated using the entire number of viable seeds (germinated + TTC-positive), demonstrated the same level of significant differences between treatments as the presented results based on numbers of only germinated seeds (results not presented).

\section{Differences in germination between populations}

The germination success under conditions which were favourable according to the results of the previous test was different for seeds of the populations studied. Seeds from LG showed the highest germination percentage (about $70 \%$ ) whereas seeds from LWW and PO exhibited the lowest one (about 37\%). Differences in the germination percentage between the populations from LG and LS on the one hand and populations from PO and LWW on the other were significant. The population from NS showed an intermediate value of germination percentage, albeit without statistical significance (Table 2). The dynamic of germination was similar for all populations, with the most seeds germinated between the 4th and the 10th day of incubation (Fig. 5). Regarding germination velocity, the abovementioned differences between populations were also significant. Timson's index for the population NS was significantly greater than for PO and LWW but significantly lower than for LG and LS (Table 2).

\section{Germination under the litter layer}

We found significant differences in seedling establishment with a dependence on litter and the maternal population (Table 3, Fig. 6). The response of different populations to the litter layer was similar. There was no significant interaction between the two factors. Seeds from the site LWW showed a low germination percentage, such as in the previous test, whereas those from LG (with the tallest maternal plants and heaviest seeds) were characterized by a comparatively high germination percentage. The overall germination success was significantly dependent on the litter layer: The highest germination percentage was observed in pots without litter (it was significantly higher than in all other litter treatments), and the lowest germination percentage could be found under a reed litter layer of $600 \mathrm{~g} / \mathrm{m}^{2}$ (Table 3, 
Fig. 3 Height $(\mathrm{cm})$ of maternal plants (A), seed weight (mg; B) and flight ability (seed width $\times$ length/pappus diameter; C) from the different analysed populations (PO - Pottenbrunn, LWW Waldwiese, LS - Schöne Wiese, LG - Glasgrabenwiese, NS Lake Neusiedl). Significant differences are marked with different letters. Mean, standard error (box) and standard deviation (whiskers) are shown. Overall significance (Kruskal-Wallis test): $\mathrm{A}-H=143.03, P<0.001 ; \mathrm{B}-H$ $=30.61, P<0.001 ; \mathrm{C}-H=$ 62.67, $P<0.001$.
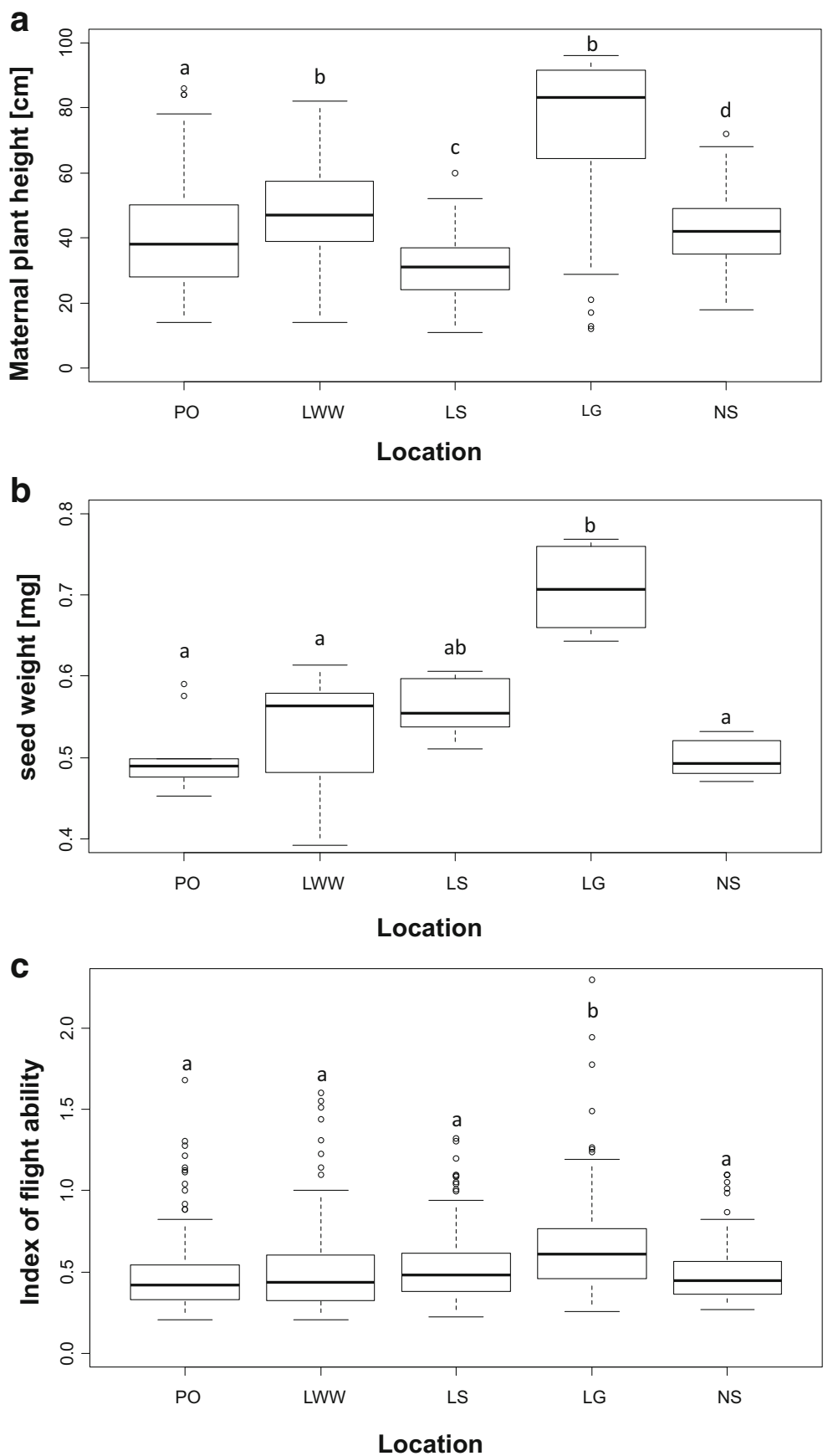

Fig. 6). The germination percentage under herb litter was significantly higher than under reed litter, and also higher than under small sedge litter of the same thickness of $300 \mathrm{~g} / \mathrm{m}^{2}$. However, this difference was not significant for most of the populations. The difference between reed and small sedge litter was also not significant.

\section{Discussion}

Seed morphology, maternal effects

All five populations studied were vigorous and contained dozens to hundreds of flowering stems. The critical value of shading for plants in non-forest 
Fig. 4 Comparison of germination percentages of $V$. dioica seeds from the population NS (Lake Neusiedl) regarding the factors temperature ('spring' with a $15 / 5^{\circ} \mathrm{C}$ and $12 /$ 12-h day/night rhythm and 'summer' with a $25 / 15^{\circ} \mathrm{C}$ and $15 /$ 9-h day/night rhythm), light (light vs darkness) and cold stratification (yes/no). Means and $95 \%$ confidence intervals (whiskers) are shown.
Light

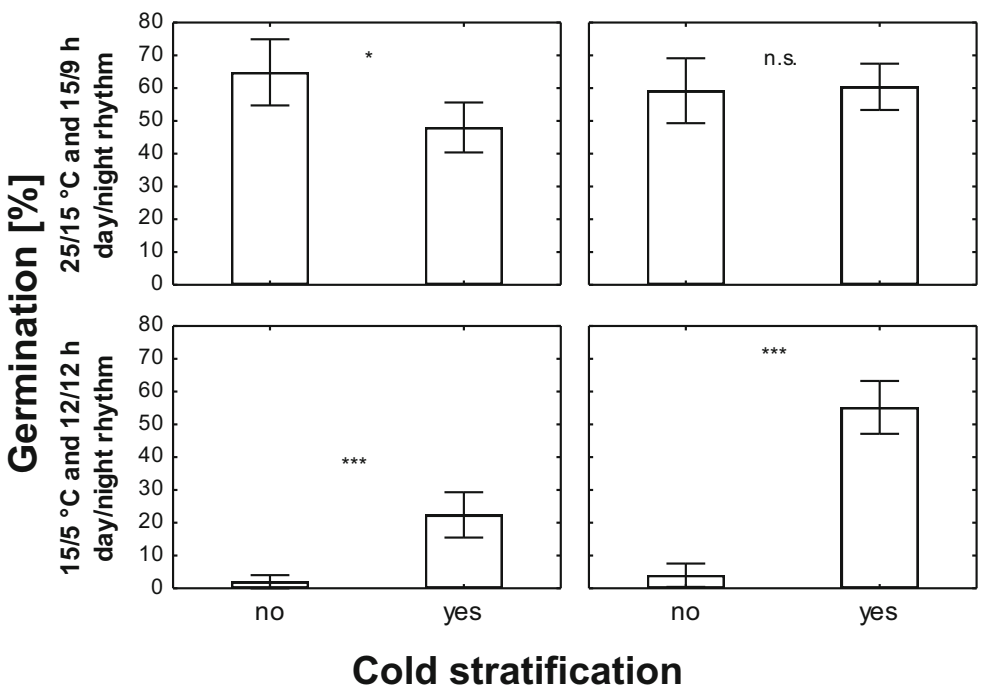

communities (i.e. the light saturation point) is expected to be about $30 \%$ of the full light (Kotowski and Van Diggelen 2004). In our study, at $15-\mathrm{cm}$ vegetation height, values below this point were measured at only one site (LG). This population differed from the other sites with regard to both the tallness of maternal plants and seed traits. We assume that the subordinate status of $V$. dioica against strong competitors was mainly considered by observations to stem morphology (leaf rosettes as main assimilation organs not taller than $10-15 \mathrm{~cm}$ )

Table 2 Differences in germination between populations. Comparisons of germination percentage (A) and germination velocity (Timson's index; B.) for five populations of Valeriana dioica (PO - Pottenbrunn, LWW - Waldwiese, LS - Schöne Wiese, LG Glasgrabenwiese, NS - Lake Neusiedl). There were twelve replicates (Petri-dishes with 25 seeds each) per population. Results of Tukey HSD post hoc tests; mean, standard deviation $(S D)$ and $P$ values $(P<0.5, P<0.01, P<0.001$, n. s. - non-significant $)$ are shown.

\begin{tabular}{lllllll}
\hline NS & 49.7 & 6.6 & ns & ns & ns & ns \\
\hline
\end{tabular}

B

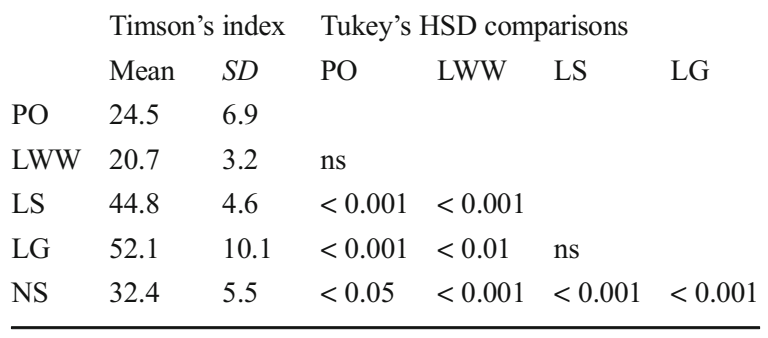

and occurrence in grassland communities of different successional stages (Schrautzer and Jensen 2004). Lower light availability, caused by shading by reed species and tall-growing herbs at abandoned fen sites, is the main trigger for the disappearance of the subordinate species from an ecosystem (e.g. Schrautzer and Jensen 2004; Rosenthal 2010). At the observed sites, however, $V$. dioica plants could invest in longitudinal stem growth and were successful in shade avoidance. As LG is considered a comparatively highly productive system with a good nutrient supply, this behaviour of subordinate species is not unexpected (Rasran et al. 2007).

The status of $V$. dioica as a subordinate species with an intermediate life strategy can only be completely described under consideration of its generative reproduction. According our observations, seeds produced at LG were heavier than at sites with less light competition. This can be seen not only as a consequence of better resource availability during fruit development (Winn 1991; Eriksson 1999), but also as an adaptation to germination under impeded conditions such as a thick litter layer and shading (e.g. Eriksson 1995). Species with heavier seeds are more likely to establish at a site in spite of litter (Jensen and Gutekunst 2003), as they possess more resources to build a taller seedling able to overcome the litter layer. This ability is normally considered a species-specific trait (e.g. Egawa and Tsuyuzaki 2013), but it can be discussed in the context of intraspecific plasticity. The relocation of resources from stem growth (shade avoidance) to greater seed 
Fig. 5 Cumulative percentage of germinated Valeriana dioica seeds from different populations (PO - Pottenbrunn, LWW Waldwiese, LS - Schöne Wiese, LG - Glasgrabenwiese, NS Lake Neusiedl) over time. Means of twelve replicates (Petri-dishes with 25 seeds each) per population and $95 \%$ confidence intervals (whiskers) are shown. Temperature and light conditions: $25 / 15^{\circ} \mathrm{C}$ and $15 / 9 \mathrm{~h}$ day/night; pre-treatment: cold stratification.

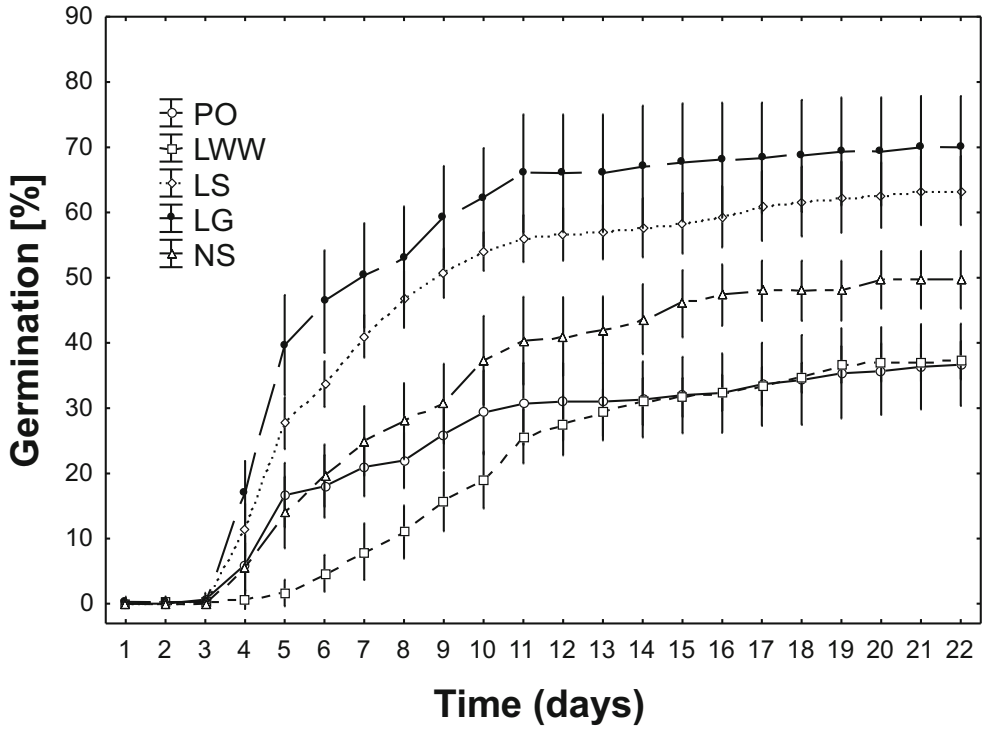

mass (better ability to germinate though the litter layer) would explain the high germination percentage of seeds from the LS site. The population at LS had the lowest light competition pressure, so it did not have to invest much into linear growth and more resources could be used for seed production.

Wind dispersal potential is usually derived from the release height and fall velocity of diaspores (Tackenberg et al. 2003). Usually, these traits are given for a plant species (as mean of 10-100 values of single diaspores) and are not subject to intraspecific variability. For this reason, we used morphological parameters of fruits to evaluate differences in flight ability between populations. The relation between seed size and pappus diameter (comparatively larger seeds with a small pappus) was lower at the LG site and thus less convenient for long-distance wind dispersal than at the other sites. At the same time, this population was characterized by

Table 3 Effects of the litter layer on the germination and early establishment of $V$. dioica seeds from five populations. Results of ANOVA (performed as a linear mixed model). Sums of squares, degrees of freedom, $F$-values and $P$-values $(P<0.001$, n.s. - non significant) are shown.

\begin{tabular}{lllll}
\hline ANOVA results & Sum of squares & D.f. & $F$ & $P$ \\
\hline Site & 160.56 & 4 & 8.7444 & $<0.001$ \\
Treatment (litter) & 362.44 & 3 & 26.3189 & $<0.001$ \\
Site*treatment & 70.27 & 12 & 1.2757 & n.s. \\
Residuals & $1,101.69$ & 240 & & \\
\hline
\end{tabular}

taller stems. The assumption that maternal individuals exposed to stronger competition for light increase the proportion of lightweight seeds suitable for dispersal beyond the borders of the current ecosystem could not be confirmed.

\section{Effects of light and temperature on germination}

In general, we found that for the germination of V. dioica seeds light is not an essential prerequisite. This species can be categorized as 'dark germinating', in contrast to the majority of wetland species, which demand at least a short light impulse (Grime 1981; Baskin et al. 1989; Jensen 2004; Kettenring et al. 2006). The ability to germinate without light is often considered characteristic for strong competitors or plants with comparatively heavy seeds (Thompson et al. 1993; Milberg et al. 2000). Such species are less dependent on additional disturbance as a factor providing gaps for germination. It could be, however, a disadvantage for the species, regarding its ability to persist as seeds in the soil (Jankowska-Blaszczuk and Daws 2007). In seed bank studies in areas where $V$. dioica occurred, this species was detected solely in the actual vegetation and not as seeds in the soil (e.g. Waesch 2006). Thompson et al. (1997) also regard the seed bank type of V. dioica as transient. Thus, this species is highly dependent on the availability of suitable germination conditions immediately after seed release. However, in our experiments, a portion of still-viable seeds did not germinate, so later 


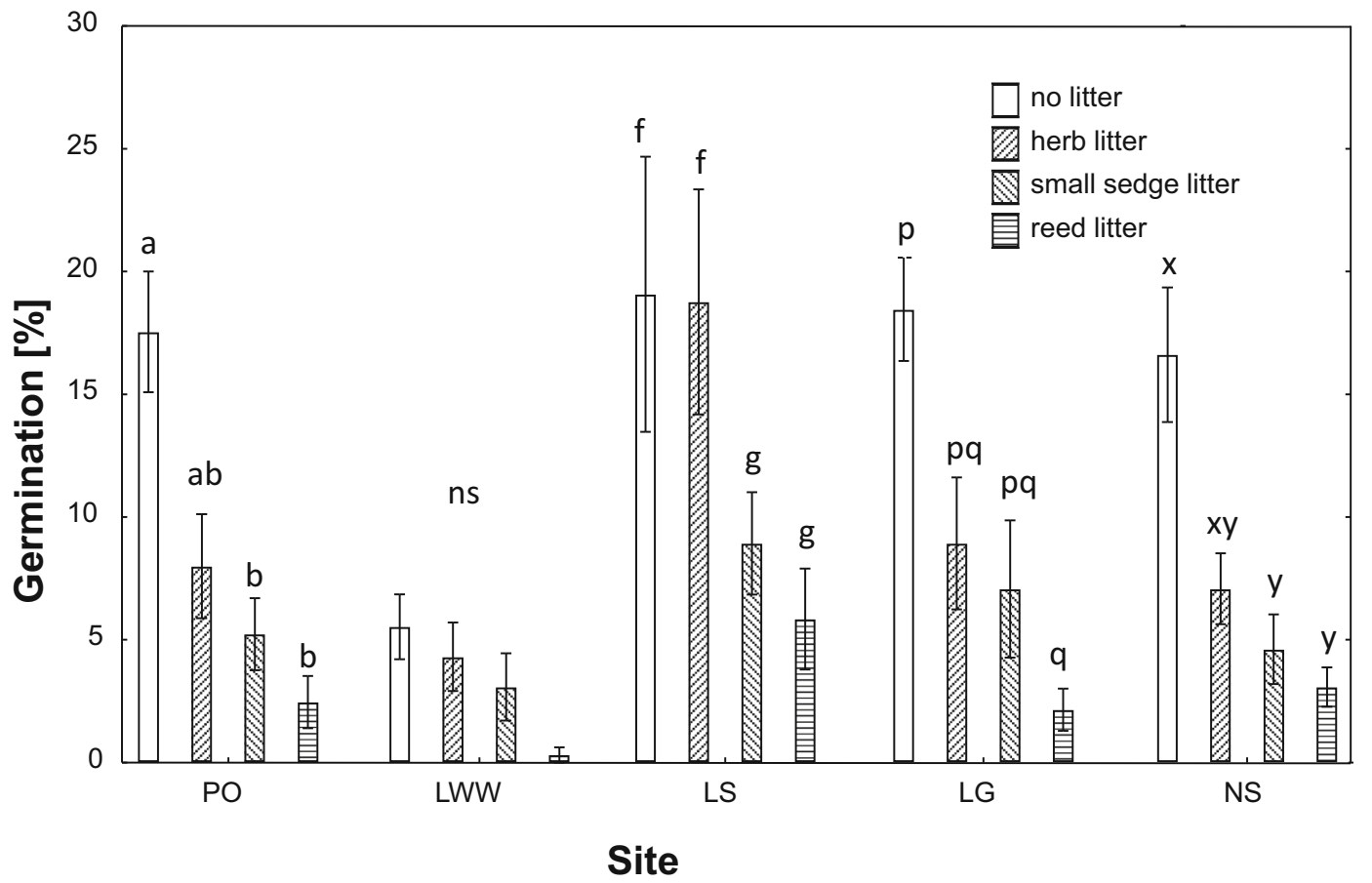

Fig. 6 Percentage of germinated Valeriana dioica seeds from different populations (PO - Pottenbrunn, LWW - Waldwiese, LS - Schöne Wiese, LG - Glasgrabenwiese, NS - Lake Neusiedl) under different litter conditions - open control (no litter), herb litter (300 g dry weight per $\mathrm{m}^{2}$ ), small sedge litter (300 g dry weight per

germination (out of the seed bank) cannot be fully excluded. A germination rate of more than $30 \%$ (up to $70 \%$ for some populations) is clearly higher than in the majority of fen grassland species (Patzelt et al. 2001).

In cases of abandonment of wet meadows, $V$. dioica is known to skip the unfavourable phase (clonal, dominated by reed) and to appear again in later successional stages such as alder and willow carrs (compare Jensen and Schrautzer 1999). To reach these sites, V. dioica has either to spread from other locations (via long-distance dispersal), or to survive as a seed in soil for a comparatively long time, waiting for appropriate growing conditions. The latter seems to be doubtable, as $V$. dioica builds only a transient seed bank (see above). Thus, $V$. dioica can be dispersal-limited in the long run and microsite-limited regarding generative reproduction in the current population, especially in the course of ongoing succession.

We expected to find the lowest light competition conditions, and best chances for the establishment of juvenile plants of $V$. dioica twice a year, in early spring before the canopy of meadow plants is developed and in $\left.\mathrm{m}^{2}\right)$ and reed litter $\left(600 \mathrm{~g}\right.$ dry weight per $\left.\mathrm{m}^{2}\right)$. Means and standard errors (whiskers) are shown. Significant differences between litter treatments within each population are marked with different letters.

summer directly after mowing. Already established vegetative rosettes of $V$. dioica follow the same strategy of seasonal avoidance of light competition against dominant reed species (compare Anten and Hirose 1999). According to the performed tests, V. dioica is able to germinate throughout the year: in summer shortly after the seeds are ripe and in spring after cold stratification, which is a common strategy for many plants in temperate wetlands (Brändel and Jensen 2005; Baskin and Baskin 2014). Various plants of European fens follow one or both germination strategies ('warm germination' induced by high temperatures and less temperaturedependent germination after cold stratification; Fernndez-Pascual et al. 2013, Fernández-Pascual 2016). The short storage between seed collection and the start of germination tests was also in accordance with natural conditions after seed release (e.g. if seeds remain in the vegetation or the litter layer and it takes some time for them to reach the soil). Secondary or deep dormancy (sensu Baskin and Baskin 2014) is probably not induced in $V$. dioica, in contrast to some wetland sedges (Schütz and Rave 1999), which also fits to the 
observations that $V$. dioica forms only a transient seed bank. Entirely, the assignment to a single form of stratification is comparatively improbable and both high and low temperatures can be suitable for germination.

\section{Effects of litter}

As light impulses were not essential for the germination of $V$. dioica seeds, the effect of litter is expected to be mainly of mechanical nature. Litter can not only hamper the growth of seedlings, but it also plays a role in capturing large, plumed achenes, which fail to reach the soil layer (see e.g. Spackova et al. 1998; Donath and Eckstein 2010). In comparison to the response of several other herbaceous species on the litter layer (Jensen and Gutekunst 2003), V. dioica appears to show a reaction, typical for plants of late successional stages, even though it has medium-sized seeds. The differences to the treatment without litter are significant, but there is still a comparatively high number of seedlings appearing in spite of the litter layer. Not only the quantity, but also the quality of litter appears to play an important role in the germination of $V$. dioica. The origin of litter influences the differences in litter decomposition more than environmental conditions (temperature, precipitation). Dicotyledonous herbs generally show much higher decomposition rates than monocots (Cornwell et al. 2008). Litter of Phragmites and Carex species tends to decompose more slowly than that of herbs (Longhi et al. 2008). Litter of dicotyledonous herbs is, by contrast, less likely to reduce the germination of subordinated plants and mainly affects the size of seedlings rather than their numbers (Olson and Wallander 2002). Adaptations to germination in shaded sites with a thick, but easily decomposable, litter layer would also fit with the occurrence of $V$. dioica in alder carrs. Alder and willow carrs could even be the primary habitats of V. dioica and several other fen meadow species.

\section{Conclusions}

The regeneration niche of $V$. dioica can be described as follows: The species is able to germinate both in summer (directly after seed release) and in early spring (after cold stratification). Recolonization via anemochorous diaspores with a high dispersal capacity seems to be the main strategy of $V$. dioica, instead of 'dispersal in time', although increasing light competition did not lead to the development of fruits, which are more suitable for flying (with a greater flight ability) and thus for longdistance dispersal. Populations with heavier seeds, however, showed significantly higher germination percentages and greater ability to overcome the litter layer. Reestablishment in sedge- and reed-dominated communities (e.g. after the abandonment of fen meadows) is strongly hampered by litter. Abandonment of regular management (including removal of mown material) would lead to the ageing of the population and finally local extinction. Otherwise, persistence or reestablishment in communities dominated by dicotyledonous herbs (including alder carrs) is possible even though light conditions for the maternal plants may not be better there.

Acknowledgements We thank Alexander Mrkvicka and Florian Soritz from the forestry direction Lainz, and Ingrid Leutgeb-Born from the environmental agency of Sankt Pölten for access to the study areas and V. dioica-populations. We also thank Dr Kati Vogt and three anonymous reviewers for helpful remarks to the manuscript. All experiments comply with the current laws of Austria.

Funding information Open access funding provided by University of Natural Resources and Life Sciences Vienna (BOKU).

Open Access This article is distributed under the terms of the Creative Commons Attribution 4.0 International License (http:// creativecommons.org/licenses/by/4.0/), which permits unrestricted use, distribution, and reproduction in any medium, provided you give appropriate credit to the original author(s) and the source, provide a link to the Creative Commons license, and indicate if changes were made.

\section{References}

Anten NPR, Hirose T (1999) Interspecific differences in aboveground growth patterns result in spatial and temporal partitioning of light among species in a tall-grass meadow. $J$ Ecol 87:583-597

Baskin CC, Baskin JM (2014) Seeds: ecology, biogeography, and evolution of dormancy and germination. 2nd edition. Academic press, San Diego

Baskin JM, Baskin CC, Spooner DM (1989) Role of temperature, light and date: seeds were exhumed from soil on germination of four wetland perennials. Aquatic Bot 353:387-394

Bosy JL, Reader RJ (1995) Mechanisms underlying the suppression of forb seedling emergence by grass (Poa pratensis) litter. Funct Ecol 635-639

Brändel M, Jensen K (2005) Effect of temperature on dormancy and germination of Eupatorium cannabinum L. achenes. Seed Sci Res 15:143-151

Cerabolini BEL, Pierce S, Verginella A, Brusa G, Ceriani RM, Armiraglio S (2016) Why are many anthropogenic 
agroecosystems particularly species-rich? Pl Biosyst 150 : $550-557$

Cohen D, Levin SA (1987) The interaction between dispersal and dormancy strategies in varying and heterogeneous environments. In Mathematical topics in population biology, morphogenesis and neurosciences. Springer, Berlin, Heidelberg, pp 110-122

Cornwell WK, Cornelissen JH, Amatangelo K, Dorrepaal E, Eviner VT, Godoy O, Hobbie SE, Hoorens B, Kurokawa H, Pérez-Harguindeguy N, Quested HM (2008) Plant species traits are the predominant control on litter decomposition rates within biomes worldwide. Ecol Letters 111:1065-1071

Cottrell HJ (1947) Tetrazolium salt as a seed germination indicator. Nature 159:748

Donath TW, Eckstein RL (2010) Effects of bryophytes and grass litter on seedling emergence vary by vertical seed position and seed size. Pl Ecol 207:257-268

Egawa C, Tsuyuzaki S (2013) The effects of litter accumulation through succession on seed bank formation for small-and large-seeded species. $J$ Veg Sci 24:1062-1073

Eriksson O, Ehrlén J (1992) Seed and microsite limitation of recruitment in plant populations. Oecologia 91:360-364

Eriksson O (1995) Seedling recruitment in deciduous forest herbs: the effects of litter, soil chemistry and seed bank. Flora 190: $65-70$

Eriksson O (1999) Seed size variation and its effect on germination and seedling performance in the clonal herb Convallaria majalis. Acta Oecol 20:61-66

Facelli JM, Pickett ST (1991) Plant litter: its dynamics and effects on plant community structure. Bot Rev 57:1-32

Facelli JM, Facelli E (1993) Interactions after death: plant litter controls priority effect in a successional plant community. Oecologia 95:277-282

Fernández-Pascual E, Jiménez-Alfaro B, Díaz-González E (2013) The temperature dimension of the seed germination niche in fen wetlands. Pl Ecol 214:489-499

Fernández-Pascual E (2016) Comparative seed germination traits in bog and fen mire wetlands. Aquatic Bot 130:21-26

Galvánek D, Lepš J (2012) The effect of management on productivity, litter accumulation and seedling recruitment in a Carpathian mountain grassland. Pl Ecol 213:523-533

Grime JP (1974) Vegetation classification by reference to strategies. Nature 250:26-31

Grime JP (1981) A comparative study of germination characteristics in a local flora. $J$ Ecol 69:1017-1059

Grubb PJ (1977) The maintenance of species-richness in plant communities: the importance of the regeneration niche. Biol Rev 52:107-145

Hegi G (2008) Illustrierte Flora von Mitteleuropa. Volume VI, part 2A. 2nd edition. Weissdorn-Verlag, Jena

Huber H, Wiggerman L (1997) Shade avoidance in the clonal herb Trifolium fragiferum: a field study with experimentally manipulated vegetation height. $P$ E Ecol 130:53-62

Imbert E, Ronce O (2001) Phenotypic plasticity for dispersal ability in the seed heteromorphic Crepis sancta (Asteraceae) Oikos 93:126-134

Jankowska-Blaszczuk M, Daws MI (2007) Impact of red: far red ratios on germination of temperate forest herbs in relation to shade tolerance, seed mass and persistence in the soil. Funct Ecol 21:1055-1062
Jensen K, Gutekunst K (2003) Effects of litter on establishment of grassland plant species: the role of seed size and successional status. Basic Appl Ecol 4:579-587

Jensen K (2004) Dormancy patterns, germination ecology, and seed-bank types of twenty temperate fen grassland species. Wetlands 24:152-166

Jensen K, Schrautzer J (1999) Consequences of abandonment for a regional fen flora and mechanisms of successional change. Appl Veg Sci 2:79-88

Kettenring KM, Gardner G, Galatowitsch SM (2006) Effect of light on seed germination of eight wetland Carex species. Ann Bot (Oxford) 98:869-874

Kotowski W, van Diggelen R (2004) Light as an environmental filter in fen vegetation. $J$ Veg Sci 15:583-594

Longhi D, Bartoli M, Viaroli P (2008) Decomposition of four macrophytes in wetland sediments: Organic matter and nutrient decay and associated benthic processes. Aquatic Bot 89:303-310

Ma Y, Wang J, Zhang J, Zhang S, Liu Y, Lan H (2017) Seed heteromorphism and effects of light and abiotic stress on germination of a typical annual halophyte Salsola ferganica in Cold Desert. Frontiers Pl Sci 8:2257

McPeek MA, Holt RD (1992) The evolution of dispersal in spatially and temporally varying environments. Amer Naturalist 140:1010-1027

Milberg P, Andersson L Thompson K (2000) Large seeded species are less dependent on light for germination than small-seeded ones. Seed Sci Res 10:99-104

Münzbergová Z, Herben T (2005) Seed, dispersal, microsite, habitat and recruitment limitation: identification of terms and concepts in studies of limitations. Oecologia 145:1-8

Olson BE, Wallander RT (2002) Effects of invasive forb litter on seed germination, seedling growth and survival. Basic Appl Ecol 3:309-317

Patzelt A, Wild U, Pfadenhauer J (2001) Restoration of wet fen meadows by topsoil removal: vegetation development and germination biology of fen species. Restorat Ecol 9:127-136

Rasran L, Vogt K, Jensen K (2007) Effects of litter removal and mowing on germination and establishment of two fengrassland species along a productivity gradient. Folia Geobot 42:271-288

R Development Core Team (2018) R: A language and environment for statistical computing. R Foundation for Statistical Computing, Vienna, Austria

Royal Botanic Gardens Kew (2018) Seed Information Database (SID). Version 7.1. Available from http://data.kew.org/sid (Accessed November 2018)

Rosenthal G (2010) Secondary succession in a fallow central European wet grassland. Flora, Morphol Distrib Funct Ecol Pl 205:153-160

Shipley B, Keddy PA, Moore DRJ, Lemky K (1989) Regeneration and establishment strategies of emergent macrophytes. J Ecol 77:109 3-1110

Schütz W, Rave G (1999) The effect of cold stratification and light on the seed germination of temperate sedges (Carex) from various habitats and implications for regenerative strategies. Pl Ecol 144:215-230

Schratt L (1990) Rote Liste gefährdeter Farn-und Blütenpflanzen Niederösterreichs. Inst. für Botanik der Univ. Wien 
Schrautzer J, Jensen K (2004) Relationship between light availability and species richness during fen grassland succession. Nordic J Bot 24:341-353

Schrautzer J, Fichtner A, Huckauf A, Rasran L, Jensen K (2011) Long-term population dynamics of Dactylorhiza incarnata (L.) Soó after abandonment and re-introduction of mowing. Flora 206:622-630

Slezák M, Hrivnák R, Petrášová A, Dítě D (2013) Variability of alder-dominated forest vegetation along a latitudinal gradient in Slovakia. Acta Soc Bot Poloniae 82:25

Špačková I., Kotorová I, Lepš J (1998) Sensitivity of seedling recruitment to moss, litter and dominant removal in an oligotrophic wet meadow. Folia Geobot 33:17-30

Tackenberg O, Poschlod P, Bonn S (2003) Assessment of wind dispersal potential in plant species. Ecol Monogr 73:191-205

Thompson K, Band SR Hodgson JG (1993) Seed size and shape predict persistence in soil. Funct Ecol 7:236-241

Thompson K, Bakker JP, Bekker RM (1997) The soil seed banks of North West Europe: methodology, density and longevity. Cambridge University Press, Cambridge
Tilman D (1988) Plant strategies and the dynamics and structure of plant communities. Princeton University Press, Princeton, New Jersey

Waesch G (2006) Untersuchungen zum Diasporenvorrat unterschiedlich genutzter Wiesen im Thüringer Wald - kann die Samenbank eine Regeneration von Grasland bewirken? [Seed bank studies from meadows in the Thuringian Forest (Germany) subjected to different cultivation regimes - can an entire grassland regenerate from a seed bank?] Tuexenia 26: 275-295

Winn AA (1991) Proximate and ultimate sources of withinindividual variation in seed mass in Prunella vulgaris (Lamiaceae). Amer J Bot 78:838-844

Publisher's Note Springer Nature remains neutral with regard to jurisdictional claims in published maps and institutional affiliations. 